\title{
Editorial
}

\section{La crisis del sector agrario}

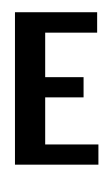

I paro nacional agrario, que ocurrió en la segunda quincena de agosto, demostró una vez más que los problemas del campo colombiano no son recientes sino que se remontan varias décadas atrás; sin embargo, con la apertura económica de los años noventa y los tratados de libre comercio (TLC) queha firmado el país en los últimos años, la situación ha tendido a agudizarse.

La apertura económica inspirada en el modelo neoliberal, se fundamenta en el argumento de que el libre comercio y la especialización en la producción de bienes que tengan ventajas comparativas, beneficia a todos los países que participan en el comercio. Por ello, en el caso dela agricultura, se arrasó con la producción detrigo y cebada, entreotros productos, porquese afirmaba que dadas las condiciones que el país presentaba para producirlos, era mejor importarlos.

Los partidarios de la apertura económica sostienen que lo que el país quiera producir, lo que decida comprar en el exterior, se puede determinar comparando los costos relativos internos con los costos externos tanto de los bienes que se producen como de los que se adquieren en el exterior $y$, de esta forma, se conseguiría una asignación de recursos más eficiente, que traería consigo efectos positivos en la estructura productiva. De hecho, eso es obvio, en un mercado libre, en el cual se ha eliminado todo tipo de interferencias y en el que los precios son los que determinan quéimportar y qué exportar. En el caso colombiano no fue así, ya que los países con los cuales se realiza el intercambio comercial (en especial los desarrollados) no modificar on su estructura proteccionista y de subsidios a la producción agrícola, lo que se tradujo en una apertura hacia adentro (es decir, que incentivó máslas importaciones de productos foráneos que las exportaciones de productos colombianos). Lo anterior trajo como consecuencia que en la primera década del período aperturista, se dejó de sembrar un millón de hectáreas.

De otro lado, de los TLC, concebidos como un pacto entre iguales, no se han sentido sus efectos en su totalidad, debido a que incluyen una desgravación arancelaria gradual de los diferentes productos, que, para algunos casos, es de hasta diecisiete años. Es previsible que su impacto se intensifique progresivamenteen detrimento de la producción agropecuaria, sobre todo de la mediana y pequeña de baja productividad. Lo anterior es predecible en la medida que el TLC con Estados Unidos elimina, desde un principio, los aranceles para más del $50 \%$ de los bienes que este país exporta a Colombia. Esto se ha reflejado en el crecimiento de las importaciones agrícolas procedentes de ese país, ya que entre junio de 2012 e igual periodo de 2013, éstas crecieron en un 127\%. En el caso de las negociaciones con los países de la Alianza Pacífico, el Gobierno actual firmó una desgravación del 92\%.

Los compromisos pactados en los TLC (en particular, los suscritos con Estados Unidos y la Unión Europea) en lo referente a los apartados agrarios y conexos, no son favorables a las exportaciones colombianas. Tanto EE.UU. como la UE subsidian considerablemente su producción agrícola, y si a esto 
le agregamos el alto componente tecnológico y la infraestructura vial, entre otros aspectos, es obvio que cuentan con mejores condiciones para colocar sus productos en el mercado nacional. Si comparamos las ayudas para el agro colombiano con las de EE.UU. y las de la UE, encontramos que en nuestro país, ellas estaban representadas,básicamente, en aranceles y no tanto en subsidios directos como sí ha sido en los dos bloques comerciales mencionados. De otro lado, una vez se firmaron los tratados, tanto EE.UU. como la UE se comprometier on con el Gobierno nacional a renunciar al arancel del $23 \%$-tarifa que les cobraban a las exportaciones colombianas- y nosotros al $77 \%$, que es el arancel que Colombia cobraba a las importaciones procedentes de dichos países. Sin embargo, los subsidios entregados por ellos a sus productores siguen siendo muy altos en comparación con los incentivos que el Gobierno nacional otorga a los productores agrícolas. Lo anterior demuestra el gran desequilibrio que existe en favor de los productores de los países desarrollados.

Los principios en que se basan tanto la apertura económica como los tratados de librecomercio, tienen que ver con el libre mercado, premisa central dentro del planteamiento neoliberal; pero, como lo plantea Joseph Stiglitz, dicho precepto es una "farsa". Esto explica, en su parecer, que la ronda DOHA para el desarrollo de la Organización Mundial del Comercio - desde que se lanzó hace años- haya fracasado, debido a que ha sido torpedeada por la negativa de EE.UU. de eliminar las subvenciones a la agricultura.

Dehecho, la crisis agraria también tiene que ver con otros problemas como son la tenencia de la tierra, el rezago tecnológico, la falta de asistencia técnica, la infraestructura - no solo de carreteras, sino también para la poscosecha-, riego e información, entre otros factores. Otro elemento que ha afectado notoriamente, en la última década, al agro colombiano, es la revaluación del peso. Según el Banco de la República, el precio promedio del dólar en el 2003 fue de 2.873, mientras que para 2013 fue de 1.874 , es decir, que en lo transcurrido de la última década la revaluación del peso colombiano fue de $53,3 \%$ respecto del dólar. La alta apreciación del peso generó incrementos sustanciales de las importaciones agrícolas y desestimuló las exportaciones del mismo sector.

La crisis del sector agropecuario ha ocasionado que las condiciones de vida de los campesinos sean cada vez más difíciles. Un efecto inmediato de la crisis ha sido la caída de los ingresos netos que reciben, los cuales, muchas veces, no alcanzan a cubrir los costos de producción, a lo que hay que agregar las altas obligaciones crediticias, lo que explica que un grupo considerable, en especial los más pequeños agricultores, desarrolle su actividad obteniendo pérdidas o apenas recibien do lo mínimo para subsistir.

En suma, la crisis rural es compleja. A medida que pasa el tiempo se incrementa la brecha social entre el campo y la ciudad. Según el DANE, en 2012, el porcentaje de las personas en condiciones de pobreza en las cabeceras municipalesera de $28,4 \%$, mientras que en las áreas rurales se elevó al $46,8 \%$, siendo el promedio nacional de $32,7 \%$. La pobreza extrema también es más alta en el sector rural frente al urbano: mientras en el primero es del $22,8 \%$, en el segundo es de $6,6 \%$, lo que contrasta con el promedio nacional de $10,4 \%$.

De otro lado, el DANE reportó que para 2012 los ingresos mensuales de las familias en las cabeceras municipales fue de $\$ 590.661$, mientras que en el sector rural se situó en $\$ 207.235$, cifra distante del promedio nacional: $\$ 500.531$.

LUIS EUDORO VALLEJO ZAMUDIO

Director Revista Apuntes del CENES 